\title{
The Total Synthesis of Delphinine: Resolution of the Racemic Relay Compound into Optical Anti- podes by an Asymmetric Reaction
}

We have described recently the total synthesis of the racemate $1 \mathrm{a}$ and its identification with the readily available optically active delphinine degradation product $1 b^{1}$. Since we wished to use the naturally derived material as a relay compound for the synthesis of various delphinium alkaloids, it was imperative to achieve the resolution of the totally synthetic racemate into optical

liberated from the oxalate and recrystallized to a constant melting point of $144.5^{\circ} \mathrm{C}$ from ether. This melting point was undepressed by admixture of the 'natural' free base $1 \mathbf{b}$ which had an identical melting point. The 2 materials showed also identical IR- $\left(\mathrm{KBr}\right.$ and $\left.\mathrm{CHCl}_{3}\right)$, mass- and NMR-spectra, identical ORD's and identical behaviour in several TLC systems. The totally synthetic

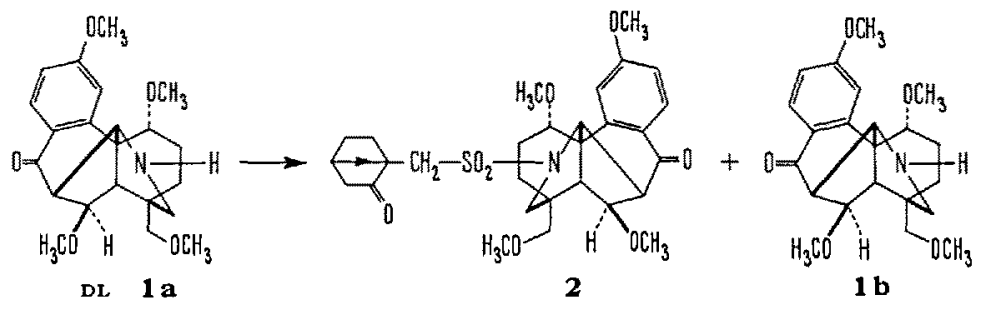

antipodes. After numerous unsuccessful attempts at resolution by conventional methods, we have noticed that if the racemate was allowed to react with $\mathrm{D}$-camphorsulphonyl chloride in pyridine, the reaction stopped when approximately $50 \%$ of the secondary amine has reacted. Isolation of the unreacted free base yielded material, which was optically active and showed an optical rotatory dispersion curve (ORD) antipodal to the ORD recorded for the natural degradation product.

Consequently, we have achieved the preparation of the totally synthetic optically active antipode $\mathbf{1} \mathbf{b}$ in the following manner: The racemate 1 a was dissolved in dry pyridine and treated with 1 mole of L-camphorsulphonyl chloride at $0^{\circ} \mathrm{C}$. The temperature was allowed to rise to $20^{\circ} \mathrm{C}$ and the mixture was kept overnight. The unreacted free base was purified by preparative TLC and converted to the acid oxalate which was recrystallized to a constant melting point of $195-196^{\circ} \mathrm{C}$ from methanol-ether. This melting point was identical with the melting point of the 'natural' degradation product oxalate and the 2 materials did not show melting point depression. The ORD's of both the synthetic and 'natural' oxalates were superimposable. Both materials gave superimposable IR-spectra ( $\mathrm{KBr}$ and $\mathrm{CHCl}_{3}$ ). Synthetic oxalate - Found: C, $60.38 ; \mathrm{H}, 6.57 ; \mathrm{N}, 2.82 \%$. Calculated for $\mathrm{C}_{24} \mathrm{H}_{31} \mathrm{O}_{9} \mathrm{~N}: \mathrm{C}, 60.36 ; \mathrm{H}, 6.54 ; \mathrm{N}, 2.93 \%$. The totally synthetic optically active free base $1 \mathbf{b}$ was
$1 \mathrm{~b}$ gave a molecular ion at $m / e=387.2046$ (calculated for $\mathrm{C}_{22} \mathrm{H}_{29} \mathrm{O}_{5} \mathrm{~N}: 387.2040$ ).

The resolution was very efficient and ca. $120 \mathrm{mg}$ of the totally synthetic optically active base $1 \mathbf{b}$ were prepared. The application of similar methods to the resolution of other racemic secondary amines is being studied.

Zusammenfassung. Das totalsynthetische Razemat DL 1 a gab bei Reaktion mit L-Camphorsulfonylchlorid das Sulfonamid 2 und die optisch-aktive Base 1 b. Die Identität dieser totalsynthetischen, optisch aktiven Base $\mathbf{1} \mathbf{b}$ mit dem entsprechenden Abbauprodukt von Delfinin wurde bewiesen.

K. Wiesner, E. W. K. JAY and LizziE POON-JAY

Natural Products Research Center,

University of New Brunswick,

Fredericton (N.B., Canada), 20 November 1970.

1 K. Wiesner, E. W. K. Jay, C. Demerson, T. Kanno, J. KŘepINSKŕ, LazzIE POON, T. Y. R. TsaI, A, VILfM and C. S. WU, Experientia 26, $1030(1970)$.

\section{Opposite Chirality of Pillaromycin A to Tetracyclines: The X-Ray Analysis of Achromycin ${ }^{1}$ Hydrochloride}

Crystal structures of tetracyclines have been reported previously by some authors. In 1959 Hirokawa et al. ${ }^{2}$ analyzed the structure of Aureomycin ${ }^{1}$ hydrochloride and a refinement of the structure was performed by DONOHUE et al. ${ }^{3}$. The structure of Terramycin ${ }^{1}$ hydrochloride was studied by TAKEUCHI and BUERGER ${ }^{4}$, and their work was extended by CID-DRESDNER ${ }^{5}$. Though these investigators have established the relative configuration of naturally occurring tetracyclines, the configuration in an absolute sense has not been reported. Meanwhile a determination of the absolute configuration of tetracyclines has been reported by DobRYNin et al.". They derived $(+)-7-$ methoxy-methylphthalide-3-carboxylic acid (II a) from Aureomycin, and spectropolarimetrically compared II a with (-)-3S-methylphthalide-3-carboxylic acid (II b), which was derived from L-o-acetylaminoatrolactinic acid, and it was revealed that the former has 3R-configuration. Since their work, the formula I has generally been accepted also in an absolute sense.

Recently, Asal et al. ${ }^{7}$ determined the structure of pillaromycin A (III), a new antibiotic isolated from the culture of Streptomyces flavovirens No. $65786^{8}$, and it was found that its structure is closely related to that of tetracyclines. However, the absolute configuration of this antibiotic, established by us from the $\mathrm{X}$-ray analysis of pillaronone monobromoacetate ${ }^{9}$ (IV), which is a deriva- 